\title{
Ophthalmic survey of a diabetic clinic: II. Requirements for treatment of retinopathy
}

\author{
R H B GREY AND A MORRIS
}

From the Bristol Eye Hospital, Bristol

SUMmaRY The eyes of 658 patients attending a district general hospital diabetic clinic were examined for retinopathy requiring treatment by photocoagulation or vitreoretinal surgery. Although the majority of patients with serious retinopathy were already under ophthalmic supervision, 39 cases (52 eyes) were found which required treatment. Eighty eyes had had previous photocoagulation, and treatment was recommended for maculopathy in 40 eyes, proliferative retinopathy in seven eyes, and combined maculopathy and proliferative retinopathy in five eyes. This suggested that existing referral criteria for photocoagulation in the population studied were reasonably accurate for proliferative retinopathy, but maculopathy was more frequently overlooked. In insulin dependent patients (IDDs) undetected maculopathy was found in $17 / 416$ eyes, $(4.0 \%)$ and in noninsulin dependent patients (NIDDs) $28 / 899$ (3.1\%). Untreated proliferative retinopathy was discovered in $5 / 416(1 \cdot 2 \%)$ IDD eyes and $7 / 899(0 \cdot 8 \%)$ of NIDD eyes. Vitreoretinal surgery was required in six eyes $(0.5 \%)$ for vitreous haemorrhage or traction retinal detachment. Equipment for the treatment of diabetic retinopathy is now almost universally available in ophthalmic departments, but time for patient management by trained staff may be inadequate. Each UK ophthalmic consultant needs approximately 100 sessions per year to monitor and treat known cases of retinopathy apart from time required to train junior staff.

The treatment of diabetic retinopathy requires the major part of the time to be devoted to retinal photocoagulation by ophthalmologists. The necessity of photocoagulation in the treatment of diabetic maculopathy ${ }^{1 \rightarrow}$ and proliferative retinopathy ${ }^{511}$ has been conclusively shown. In addition, for those cases with persistent vitreous haemorrhage or traction retinal detachment, vitrectomy and segmentation of diabetic fibrovascular tissue has been shown to improve vision in a large proportion of patients. ${ }^{12-17}$

In order to plan services for effective patient management it is necessary to know the likely work load involved in terms of photocoagulation and vitreous surgery. A study was therefore devised to examine diabetic patients in a general hospital in an attempt to define the probable resources required for management of diabetic patients.

\section{Patients and methods}

The patients studied and the methods employed have Correspondence to Mr. R H B Grey, FRCS, Bristol Eyc Hospital, Lower Maudlin Strect, Bristol BSI 2LX. been previously described. ${ }^{18}$ In brief, the entire diabetic clinic of the General Hospital at Westonsuper-Mare was examined prospectively in a purposely formed combined medical and ophthalmic clinic. The diabetic and ocular details were recorded on a proforma designed for later computer analysis. Among the data recorded were the presence and severity of retinopathy, the type of diabetic treatment the patients were receiving, previous photocoagulation treatment and whether the patients were under regular ophthalmic review (defined as examination by an ophthalmologist within the previous two years).

Diabetic maculopathy was considered treatable and recommended for laser photocoagulation if there was foveal oedema or exudates were encroaching on the fovea. Proliferative retinopathy was recommended for treatment if vasoproliferation was active, but not if previous photocoagulation had induced regression or quiescence of the proliferative process.

In order to facilitate analysis patients were assigned to one of four groups depending on insulin or non-insulin dependency (IDD or NIDD) and whether they were under ophthalmic supervision by 
an ophthalmologist: group $A$, IDD and seen by an ophthalmologist within two years; group $B$, IDD and not seen by an ophthalmologist for at least two years; group $C$, NIDD and seen by an ophthalmologist within two years; group $D$, NIDD and not seen by an ophthalmologist for at least two years.

\section{Results}

Six hundred and eighty-one patients were asked to attend the combined clinic, of which $658(96.6 \%)$ were examined. Two hundred and eight patients $(31.6 \%)$ were insulin dependent diabetics (IDDs) and $450(68.4 \%)$ were non-insulin dependent diabetics (NIDDs).

\section{RETINOPATHY AND PHOTOCOAGULATION}

The previous attendance and photocoagulation records are shown in Tables 1 and 2 .

\section{Insulin dependent patients}

Group A consisted of 86 patients whose eyes had been examined within the previous two years $(41.3 \%$ of IDDs). One hundred and nine eyes (64.5\%) of this

Table 1 Patient groups and numbers of eyes

\begin{tabular}{lcccc}
\hline & $I D D$ & $\%$ & NIDD & $\%$ \\
\hline $\begin{array}{l}\text { Eyes examined within } \\
\text { two years }\end{array}$ & Group A: 169 & $40 \cdot 6$ & Group C: 211 & 23.5 \\
$\begin{array}{l}\text { Eyes not examined } \\
\text { within two years }\end{array}$ & Group B: & $24358 \cdot 5$ & Group D: & $67975 \cdot 5$ \\
Not assessed & 40.9 & 91.0 \\
Total & 416100 & 899100 \\
\hline
\end{tabular}

IDD = Insulin dependent. NIDD=Non-insulin dependent.

Table 2 Eyes showing retinopathy

\begin{tabular}{|c|c|c|c|c|c|c|c|c|}
\hline & $\begin{array}{c}\text { Grou } \\
A\end{array}$ & & $\begin{array}{l}\text { Gro } \\
B\end{array}$ & & $\underset{C}{G r o}$ & & $\begin{array}{c}G r o \\
D\end{array}$ & \\
\hline No & & & & & & & & \\
\hline retinopathy & 60 & 35 & 5173 & 71 & 2138 & 65 & 5573 & $84 \cdot 4$ \\
\hline Retinopathy & 109 & 64 & 570 & 28 & 73 & 34 & 6106 & $15 \cdot($ \\
\hline Total & 169 & 100 & 243 & 100 & 211 & 100 & 659 & 100 \\
\hline Not assessed & 3 & & 1 & & 7 & & 2 & \\
\hline
\end{tabular}

group had retinopathy, of which 51 eyes had undergone previous photocoagulation. Twelve eyes $(7 \cdot 1 \%)$ required photocoagulation for maculopathy and three eyes $(1.3 \%)$ for proliferative retinopathy. Eleven eyes had quiescent proliferative retinopathy following previous photocoagulation.

Group B contained 122 patients whose eyes had not been examined within the past two years $(58.7 \%$ of IDDs). In this group 70 eyes $(28 \cdot 8 \%)$ showed retinopathy, of which five required treatment for maculopathy $(2 \cdot 1 \%)$ and two for proliferative retinopathy $(0 \cdot 8 \%)$. In four IDDs the presence of retinopathy could not be determined on account of opacities in the media.

\section{Non-insulin dependent patients}

Group C had 109 patients (24.2\% of NIDDs). Of the 211 eyes examined in this group $73(34.6 \%)$ showed retinopathy, and previous photocoagulation had been carried out on 29. Laser photocoagulation was recommended for 14 eyes $(6 \cdot 6 \%)$ for maculopathy and for five eyes $(2.4 \%)$ with proliferative retinopathy. One eye had persistent, quiet fibrovascular tissue following laser treatment, which did not require further photocoagulation.

Group D consisted of 41 patients $(75.8 \%$ of NIDDs). One hundred and six eyes in this group had retinopathy $(15 \cdot 6 \%)$. Fourteen eyes $(2 \cdot 1 \%)$ were recommended for treatement for maculopathy and two eyes $(0.2 \%)$ for proliferative retinopathy. The presence of retinopathy in nine NIDD eyes could not be determined.

Tables 3 and 4 show the numbers of eyes with

Table 3 Eyes with serious retinopathy recommended for treatment

\begin{tabular}{lrlllr}
\hline Group & No. & $\begin{array}{l}\text { Maculopathy } \\
\text { only }\end{array}$ & $\begin{array}{l}\text { Proliferative } \\
\text { retinopathy } \\
\text { only }\end{array}$ & $\begin{array}{l}\text { Maculopathy } \\
\text { plusproferative } \\
\text { retinopathy }\end{array}$ & Total \\
\hline A & 172 & 10 & 1 & 2 & 13 \\
B & 244 & 5 & 2 & - & 7 \\
C & 218 & 11 & 2 & 3 & 16 \\
D & 681 & 14 & 2 & - & 16 \\
Total & 1315 & 40 & 7 & 5 & 52 \\
\hline
\end{tabular}

Table 4 Eyes with proliferative retinopathy

\begin{tabular}{|c|c|c|c|c|c|c|c|c|}
\hline \multirow[t]{2}{*}{ Group } & \multicolumn{2}{|l|}{$N V D$} & \multicolumn{2}{|l|}{$N V E$} & \multicolumn{2}{|c|}{$N V D+N V E$} & \multicolumn{2}{|l|}{ Total } \\
\hline & Active & Inactive & Active & Inactive & Active & Inactive & Active & Inactive \\
\hline $\mathbf{A}$ & 1 & 11 & 2 & 3 & - & 5 & 3 & 19 \\
\hline B & - & - & 1 & - & 1 & - & 2 & - \\
\hline C & 2 & 1 & 2 & 1 & 1 & - & 5 & 2 \\
\hline D & - & - & 2 & - & - & - & 2 & - \\
\hline Total & 3 & 12 & 7 & 4 & 2 & 5 & 12 & 21 \\
\hline
\end{tabular}


serious retinopathy in all groups. There were 21 eyes in which previous photocoagulation had led to regression of active vasoproliferation and did not require further treatment although some fibrous tissue persisted. Sixty-three $(48.0 \%)$ eyes were discovered to have maculopathy, and 45 .were recommenided for photocoagulation. The remaining 18 eyes were judged to be too advanced for treatment to be beneficial.

Twelve eyes $(0.9 \%)$ were found to have active proliferative retinopathy, and all were recommended for photocoagulation. Of these 12 eyes three had disc new vessels, seven had peripheral new vessels, and two had both disc and peripheral new vessels.

Combined maculopathy and active proliferative retinopathy was seen in five eyes, all of which were recommended for laser photocoagulation. One eye was found to have a posterior retinal tear from vitreous traction, and this was treated by laser.

\section{VITRECTOMY}

Out of a total of 1315 eyes in the whole study six were recommended for vitreoretinal surgery $(0 \cdot 5 \%)$. All these patients had previously received photocoagulation, and all but one were IDD. There were five further patients with vitreous haemorrhage who were not recommended for surgery as it was thought either the haemorrhage would clear spontaneously or the underlying retinal ischaemia was too advanced for visual improvement to occur.

Six eyes $(0 \cdot 5 \%)$ had advanced diabetic eye disease and were beyond treatment.

\section{Discussion}

The management of diabetic retinopathy is a cause for concern both to physicians running diabetic clinics and to ophthalmologists. ${ }^{19}$ Prior to the survey clinic described here referral for ocular examination in Weston-super-Mare was either by general practitioners or by physicians managing the diabetic clinic. When patients had visual symptoms, or if retinopathy was noted on ophthalmoscopy, an ophthalmic opinion was requested. The low prevalence of most forms of serious retinopathy in those patients who had not had their eyes previously examined by an ophthalmologist before suggests that this method of referral is moderately efficient, at least for proliferative retinopathy. However, maculopathy tended to be overlooked in $2 \%-3 \%$ of eyes in IDDs and NIDDs. In this study more than half the IDDs were not under ophthalmic supervision (group B), and, of these, $28 \%$ had retinopathy, of which $10 \%$ needed treatment. Although this might suggest this is an 'at risk' group, those already under supervision (groups $A$ and $C$ ) had almost equal rates of treatable retinopathy. When group D was compared with group B, the prevalence of retinopathy was less, but, once it was present, the proportion requiring treatment was similar.

For ophthalmologists it would appear that the very time consuming exercise of screening large numbers of diabetics would not be justified, as relatively few additional patients would be identified for treatment of retinopathy. It would probably be more appropriate to ensure that the physicians responsible for the primary diabetic care could broadly assess retinopathy, and also for patients to have visual acuity measurements to reduce the number of missed maculopathy cases. Cases in which retinopathy is identified should probably be referred for ophthalmic opinion.

The catchment population of Weston General Hospital is approximately 92000 . The primary ophthalmic assessment of the diabetic cases attending the diabetic clinic is carried out within the same hospital. Not all diabetic patients in the district are referred to hospital by their general practitioners, and the numbers of diabetics seen in this survey $(7 \cdot 4$ per 1000 population) are lower than the estimated UK prevalence of diabetics of about 10 per $1000 .{ }^{20}$ Nevertheless the spectrum of retinopathy seen in this survey is probably similar to that found in other nonteaching district general hospitals. If the figures in this study are representative of the diabetic population as a whole, at least $8.0 \%$ of diabetic eyes will require laser photocoagulation at some time, of which approximately $80 \%$ will be for maculopathy and $20 \%$ for proliferative retinopathy. These figures are not greatly different for IDDs compared with NIDDs, although there is a slightly higher prevalence of proliferation and maculopathy in IDDs. ${ }^{18}$

The time needed for such photocoagulation treatment varies. Scobie et al. ${ }^{21}$ suggested that maculopathy requires 30 minutes per treatment session and proliferative retinopathy up to two hours, the time depending on the number of sessions, the patient's tolerance, and the operator's skill. Using these times, with which we are in broad agreement, we found that this survey produced an additional treatment requirement of 44 hours above the treatment which has already been administered, in spite of two consultant opthalmologists with an interest in diabetic retinopathy managing the diabetic patients attending the hospital. In the UK there are 412 consultant ophthalmologists serving 56 million citizens, and at the rates found in this survey each consultant might be required to give nearly 65 hours additional laser photocoagulation to diabetics. No data were collected on the fresh incidence of treatable retinopathy, and therefore it is not possible to 
calculate the long-term requirements for supervision and treatment of new cases, but the time required for monitoring patients with known retinopathy can be assessed. On a conservative assumption that a single 20-minute examination a year is necessary for background retinopathy, and, say, six visits a year are required for patients needing photocoagulation, then the clinic population studied required 193 hours per year for outpatient attendances regardless of treatment time. On a national scale each consultant could require 285 hours or 82 sessions per year to examine diabetics and a possible further 18 sessions for photocoagulation. As pointed out by Blach, ${ }^{19}$ the major limiting factor for the proper management of retinopathy is no longer equipment availability but lack of trained staff. The above calculations do not take account of time required to train junior staff in assessment or photocoagulation of diabetic retinopathy.

The number of diabetic eyes requiring vitrectomy is low $(0 \cdot 5 \%)$. However, calculating from a known 681 diabetic patients in a population of 92000 suggests that 3876 eyes may need vitrectomy in a UK population of 56 million-that is, 9 or 10 eyes per consultant ophthalmologist. If two such operations were carried out per week, 20 specialist vitrectomists would take two years to complete the work regardless of other conditions or of new diabetic cases needing vitrectomy. Owing to the expense of equipping an operating theatre for vitrectomy work it would seem reasonable to set up specialist centres, but the present number of such centres in the UK is woefully inadequate. It is to be hoped that in the future the number of eyes requiring vitrectomy will be reduced gradually as improved management by photocoagulation reduces the prevalence of uncontrolled proliferative retinopathy.

The authors would like to thank Mrs Rosemary Evans for typing the manuscript.

\section{References}

1 Whitelocke RAF, Kearns M, Blach R, Hamilton AM. The diabetic maculopathies. Trans Ophthalmol Soc UK 1979; 99; 314-20.

2 Townsend C, Bailey J, Kohner E. Xenon arc photocoagulation for the treatment of diabetic maculopathy. Br J Ophthalmol 1980; 64: 385-91.

3 Reeser F, Fleischman J, Williams GA, Goldman A. Efficacy of argon laser photocoagulation in the treatment of circinate diabetic retinopathy. Am J Ophthalmol 1981; 92: 762-7.

4 British Multicentre Study Group. Photocoagulation for diabetic maculopathy: a randomised controlled clinical trial using the xenon arc. Diabetes 1983; 32: 1010-6.

5 Cheng $\mathrm{H}$. Response of proliferative diabetic retinopathy to xenon arc photocoagulation. Trans Ophthalmol Soc UK 1976; 96: 224-7.

6 Hercules BL, Gayed II, Lucas JB, Jeacock J. Peripheral retinal ablation in the treatment of proliferative diabetic retinopathy: a three year intensive report of a randomised controlled study using argon laser. Br J Ophthalmol 1977; 61: 555-63.

7 Diabetic Retinopathy Study Research Group. Photocoagulation treatment of proliferative diabetic retinopathy. Ophthalmology (Rochester) 1978; 85: 82-106.

8 Yassur Y, Pickle LW, Fine SL, Singerman L, Orth D, Patz A. Optic disc neovascularisation in diabetic retinopathy. II. Natural history and results of photocoagulation treatment. $\mathrm{Br} J$ Ophthalmol 1980; 64: 77-86.

9 Diabetic Retinopathy Study Research Group. Photocoagulation treatment of proliferative diabetic retinopathy. Ophthalmology (Rochester) 1981; 88: 583-600.

10 Hamilton AM, Townsend C, Khoury D, Gould E, Blach RK. Xenon arc and argon laser photocoagulation in the treatment of diabetic disc neovascularisation. Trans Ophthalmol Soc UK 1981; 101: 87-92.

11 British Multicentre Study Group. Photocoagulation for proliferative diabetic retinopathy: a randomised controlled clinical trial using the xenon arc. Diabetologia 1984; 26: 109-15.

12 Boase DL, Blach RK, Fison LG, Leaver PK, McLeod D. Results of closed vitrectomy. Trans Ophthalmol Soc UK 1977; 97: 251-3.

13 Michels RG. Vitrectomy for complications of diabetic retinopathy. Arch Ophthalmol 1978; 96: 237-46.

14 Aaberg TM. Clinical results in vitrectomy for diabetic traction retinal detachment. Am J Ophthalmol 1979; 88: 246-53.

15 Michels RG, Rice TA, Rice EF. Vitrectomy for diabetic vitreous hemorrhage. Am J Ophthalmol 1983; 95: 12-21.

16 Rice TA, Michels RG, Rice EF. Vitrectomy for diabetic traction retinal detachment involving the macula. Am J Ophthalmol 1983; 95: 22-23.

17 Shea M. Early vitrectomy in proliferative diabetic retinopathy. Arch Ophthalmol 1983; 101: 1204-5.

18 Grey RHB, Malcolm N, O'Reilly D, Morris A. Ophthalmic survey of a diabetic clinic. I. Ocular findings. Br J Ophthalmol 1986; 70: 797-803.

19 Blach RK, Bloom A. Diabetic eye centres in the management of diabetic eye disease. Health Trends 1978; 10: 88-90.

20 West KM. Epidemiology of diabetes and its vascular lesions. New York: Elsevier, 1978: 127-36.

21 Scobie IN, MacCuish AC, Barrie T, Green FD, Foulds WS. Serious retinopathy in a diabetic clinic: prevalence and therapeutic implications. Lancet 1981; ii: 520-1.

Accepted for publication 11 February 1986. 